\title{
Design, Manufacturing Status, First Results of the LHC Main Dipole Final Prototypes and Steps towards Series Manufacture
}

\author{
K,Artoos, L.Bottura, P.Pessia, M.Bajko, M.Modena, O.Pagano, D.Perini, F.Savary, W.Scandale, A.Siemko, \\ G.Spigo, E. Todesco, J.Vlogaert, C.Wyss / CERN, Geneva, Switzerland
}

\begin{abstract}
This paper reports about the program of six LHC superconducting main dipole final prototypes and the steps towards series manufacture. The alsove program, launched in summer 1998, relies on collared coils manufactured by industry and cold masses assembled at the CERN Magnet $A$ ssembly Facility. Following design, stability and robustness studies, the magnet design for series manufacture features a "6-block" coil and austenitic steel collars. A general description of the magnet with its main components is given and the main working parameters and the most important manufacturing features are presented. Results of mechanical and magnetic mensurements are given as well as the performances of the lirst prototype. A comparison with results from the previous generation of dipole magnet models and prototypes is also made. Finally an outlook towards series mnnufucture is given.
\end{abstract}

\section{INTRODUCTION}

To validate the major design features selected [1] in view of the series manufacture of the 1232 LHC superconducting (SC) main dipole magnets, CERN has launched in the summer of 1998 the fabrication of $3 \times 2$ prototype collared coils in industry. These collared coils are subsequently assembled into cold masses at the CERN Magnet Assembly Facility. The first prototype dipole cold mass was tested during the summer of 1999, the assembly of the second one is in progress. It is expected to complete the assembly and testing of the remaining four prototypes by summer 2000 . This program also allows to fine-lune assembly procedures and the detail design of ancillary components with a view to minimise assenthly time and component costs. The experience and know-how gained will provide the basis for the imminent beginning of the manufacture of $3 \times 30$ series dipole magnets by industry.

\section{Descr IPTion OF THE LHC MAIN Dipole}

The dipole magnct cross-scction is shown in Fig. 1, while 1-beam tube; 2-SC coils; 3-austenitic steel collars; 4-iron yoke; 5-iron yoke "insert", 6-shrinking cylinder / He II vesscl; 7-heat exchanger tube; 8-dipole bus-bars; 9-arc quadrupole and "spool-picces" bus-bars; 10-wires for magnet protection and instrumentation.

Its main parameters aro given in Table I and the main parameters of the SC cables are given in Table II. The design studies which have lead to the selection of the above crosssection for series manufacture are reported in [2] and [3]. The dipole cold mass consists of an active part, providing two

apertures for the cold bore tubes, and of ancillary parts allowing for operation at $1.9 \mathrm{~K}$ in superfluid helium. The

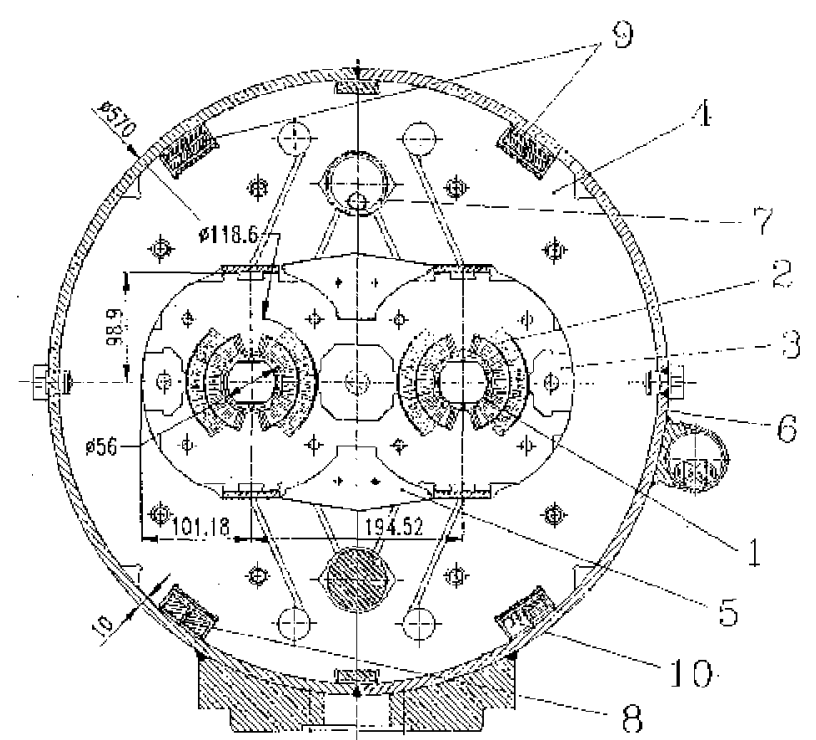

Fig. I. Cross-section of LHC serios dipoles.

active part is made of:

i) Two dipole coils, each consisting of an upper and a lower pole. Each pole consists of an inner and an outer layer, connected in series. The coils are equipped with quench heaters, to trigger a general quench of the layers in case of detection of an initial local quench.

ii) Austenitic steel (AS) line-blanked collars (3 mm thick), which confines and pre-stresses the coils, so that they strictly maintain their geometry in spite of the very high electromagnetic forces occurring during magnet testing and operation.

Items i) and ii) together with the related cold bore tubes constitute the collared coils.

iii) The 13572-mm long low-carbon iron yoke, made out of 5.8-mm-thick line-blanked laminations, split in two parts at the vertical symmetry plane. The yoke is completed at both ends, over a lefigth of $513 \mathrm{~mm}$, by AS laminations $(3 \mathrm{~mm}$ thick) to lower by about $15 \%$ the magnetic ficld at the coil ends.

iv) Two laminated iron inserts placed across the vertical symmetry plane, completing the magnetic yoke and also constituting the vertical force-carrying element between the collared coils and the yoke.

v) An AS shrinking cylinder, 14760-mm long and at least 10-mm-thick, made up of two longitudinally-welded haltcylinders (the latter manufactured without any welds), surcounding the yoke. For serios manufacture, the halfcylinders are bent to achieve, after welding, the horizontal 
TABLE [

MAIN PARAMETERS AND CIIARACTERISTICS OF THE DIPOLE COLD MASS

\begin{tabular}{|c|c|c|}
\hline & Value & Unit \\
\hline Inj. field ( $0.45 \mathrm{TeV}$ bean energy) & $0 . \$ 4$ & $\mathrm{~T}$ \\
\hline Nom. field ( 7 TeV beam energy) & 8.33 & $\mathrm{~T}$ \\
\hline Nominal current & 11800 & A \\
\hline Operating temperature & 1.9 & $\mathbf{K}$ \\
\hline Magretic length at $1.9 \mathrm{~K}$ & 14.300 & 11 \\
\hline Nom. stored energy (Lwo bores) & 7.1 & MJ \\
\hline Ultimate operational field & 9.00 & $\mathrm{~T}$ \\
\hline Nominal short sample ficld limit & 9.65 & $\mathrm{~T}$ \\
\hline Apertures axis distance at $1.9 \mathrm{~K}$ & 194.00 & mת \\
\hline Bending radius at $1.9 \mathrm{~K}$ & 2803 & m \\
\hline Apertute uxis distance at $293 \mathrm{~K}$ & 194.52 & min \\
\hline Approx. bending radius at $293 \mathrm{~K}$ & 2812 & $\mathrm{~m}$ \\
\hline Inncr ccil diameter at $293 \mathrm{~K}$ & 56,00 & m?m \\
\hline Outer coil dianeter at $293 \mathrm{~K}$ & 118.60 & $\operatorname{mm}$ \\
\hline Conthuctor blocks / pole & 6 & \\
\hline Turns / pole, inner/outer Jayer & $15 / 25$ & \\
\hline \multicolumn{3}{|l|}{ E.m. forces/coil quadrant at $8.3 \mathrm{~T}$} \\
\hline Hor. fores (inner and outer layer) & 1.7 & $\mathrm{MN} / \mathrm{m}$ \\
\hline Vertical force (inner layer) & -0.14 & $\mathrm{MN} / \mathrm{m}$ \\
\hline Vertical force (outer layer) & -0.50 & $\mathrm{MN} / \mathrm{m}$ \\
\hline Axial electromag. force on both ends at nom. field & 0.37 & $\mathrm{MN}$ \\
\hline Cold bore inner/outer dianteter at $293 \mathrm{~K}$ & $50 / 53$ & mזn \\
\hline Active part length at $293 \mathrm{~K}$ & $15: 80$ & inm \\
\hline Cold mass diamoter at $293 \mathrm{~K}$ & 570.0 & $\mathrm{~mm}$ \\
\hline Overall length with ancillaries & 16.8 & $\mathbf{m}$ \\
\hline Mass of the cold mass & $\sim 30$ & tonne \\
\hline
\end{tabular}

TABLE II

\begin{tabular}{lccc}
\multicolumn{4}{c}{ TABLE II } \\
& Inner & Outor & Unit \\
& layer & layer & \\
\hline Strand diameter & 1.065 & 0.825 & $\mathrm{~mm}$ \\
Strand Cu/SC ratio & 1.65 & 1.95 & $\mathrm{~mm}$ \\
Filament diameter & 7 & 6 & $\mu \mathrm{m}$ \\
Filaments / strand & 8800 & 6400 & \\
Number of strands & 28 & 36 & \\
Ic at 1.9 K and 10 T & 13750 & & $\mathrm{~A}$ \\
Ie at 1.9 K and 9 T & & 12950 & $\mathrm{~A}$ \\
Cable width & 15.1 & 15.1 & $\mathrm{~mm}$ \\
Keystone angle & 1.25 & 0.9 & $\mathrm{deg}$ \\
Cable mid-thickntess & 1.90 & 1.48 & $\mathrm{mmn}$ \\
Transposition pitch & 115 & 100 & $\mathrm{~mm}$ \\
\hline
\end{tabular}

curvature of the cold mass. The shrinking cylinder gives to the cold mass assembly the stiffness necessary to contain the electromagnetic forces, provides the inertia necessary to maintain to within $\pm 1 \mathrm{~mm}$ the geometry of the cold mass on its supports, and is the major part of the helium containment vessel. In its jatter function, it must be able to resist to pressures up to $2 \mathrm{MPa}$ which may oceur during a queneh.

vi) Two 50-mm-thick AS end plates, terminating the active part at both extremities, to take up the longitudinal electromagnetic forces.

\section{Manufacture of Prototype Colls}

The manufacture of prototype collared coils has been entrusted to three European firms (Ansaldo, Alstom-Jeumont and Noell). The coils have an overall length of $14567 \mathrm{~mm}$; the difference between the average azimuthal size and its actual value at any point along layers and poles, moasured under a $50 \mathrm{MPa}$ compressive load, must not exceed $\pm 25 \mu \mathrm{m}$.
For the inner and outer layer, $\mathrm{SC}$ cable lengths of $460 \mathrm{~m}$ and $750 \mathrm{~m}$ are required, respectively. To run-in tooling like windling mandrels, curing molds and the various manufacturing operations, dummy coils wound with copper cables were made fïrst.

In all the prototype coils the inner and outer layers are joined (SnAg4.5 soldering alloy, joint resistance $<1 \mathrm{n} \Omega$ at $1.9 \mathrm{~K}$ ) immediately alter the inner layer ramp. The joined cables are locked in a charged UL'TEM* box designed to position both the ramp and splice.

The coil production at the three different sites is fulfilling the necessary and required precision and reproducibility. Two manufacturers have produced coils within the toletance tange of $\pm 25 \mu \mathrm{m}$ or the transverse dimensions, $A$ thitd manufacturer is at present solving a tooling problem causing in the first layor a precision of \pm 100 Hm. The good reproducibility is evidenced by the fact that the collaring shims used for the different poles are within $\pm 0.05 \mathrm{~mm}$. This evaluation of reproducibility and precision takes also into account the small difference between the SC cables delivered to the coil manufacturers (cables from different suppliers are used for the prototype coils) and the characteristics of the major tooling (i.c. winding machines, curing molds and curing presses) presently available at the different sites.

Following the imminent start of the work for the manufacture of $3 \times 30$ cold masses, the still missing main tooling is being procured by the firms and will be available in the lirst half of next year.

\section{Coll COllaking}

One of the main results expected from the assembly of the prototypes is the optimisation of the pre-collaring and collaring procedures. During pre-collaring the collars are kept around the coils by locking rods of a diameter smatler by $I$ mm than nominal; during collaring the nominal rods are inserted. The presses foreseen for the series production will allow to insert the three nominal locking rods in a singlo operation. Two such presses are already operational at Ansaldo and Alstom-Jeumont, a third one is being procured by Nooll,

Consequently, the recent collaring at Noell of prototypes MBP2N1 (AA * collars) and MBP2N2 (AS collars) was made in two steps (application of pressute fitst on the collar sides and insertion of the side rods, followed by application of pressure at the collar centre and insertion of the central rod). During pre-collaring an expansible mandrel was used to push radially the coils against the collar cavity. Subsequently, the mandrel is removed and the cold bore tube is inserted.

In order to minimise assembly time, simpler procedures will be tested at Alstom and at Ansaldo (pre-collaring with the cold bore tube already inserted). The azimuthal coil prestress after collaring in the coil straight part of MBP2NI and MBP2N2 is reported in Table IIL.

\footnotetext{
* ULTEM is a trademark of General Elcotric, USA.

*** Aluminitum alloy
} 
TABLE III

AVRAGE PJE-STTESS AFTER COLLAFHG IN THE STRUIOHT SECTLONS OF THE MBPIN1 AND

\begin{tabular}{lcc}
\multicolumn{3}{c}{ MnP2N2 CoLlaRED Cols } \\
\hline & MBP2N1 (AA collars) & MBP2N2 (AS collars) \\
\hline Innot layer & $45 \mathrm{MPa}$ & $65 \mathrm{MPa}$ \\
Outer layer & $45 \mathrm{MPa}$ & $70 \mathrm{MPa}$ \\
\hline
\end{tabular}

The pre-stress distribution in the ends of MBP2N1 is not woll known due to the poot Young modulus measuring system then available. The measurement quality was largely improved for MBP2N2, where a pre-stress distribution in the coil onds following the law $\sigma(x)=30+\left(\sigma_{0}-30\right)(1$. $\operatorname{tg}(\pi / 4 \cdot x / 180))$ where $\sigma_{0}$ is the pre-siress in the straight part and $x$ is the distance from the end of the straight part. Distances are in millimetres and stresses in $\mathrm{MPa}$. Further input concerning the optimisation of the coil end pre-stress is being provided by the short model progtanme [4].

\section{COLD MASS ASSEMBLY}

The dipole cross-section design shown in Fig. 1 has atlowed a much easior and faster assembly of collared coils and iron bal[-yokes than the previous design [5]. The latter telied on a vertical interference of $0.14 \mathrm{~mm}$ between collars and yoke (10 compensate for the reduction in vertical size of the collared coils at bigh field, because of the unloading by electromagnetic forces of the coil pre-stress) and on a nominal yoko vertical gap of $0.52 \pm 0.05 \mathrm{~mm}$ after longitudinal welding of the shrinking cylinder. The first condition required tedious measurentents and adjustments because of the spread in collared coil height, caused by the fitting of the magnetic insert into the AA collars. The scoond condition required tight tolerances on the half circumference of the shrinking cylinder half-shells and a very precise control of the wolding shrinkage.

The first prototype (MBP2N1) of the present series of six was still equipped with aluminium collars and its yoke was assembled with laminations of non-nominal geometry, left from previous work, because of availability. Collars and yoke had however a geometry close to that shown in Fig. 1. The collared coils and the iron inserts kept together by a fixture could be inserted without any difficulties in the yoke. After welding, the avcrage azimuthal pre-stress in the shrinking cylitider was $180 \mathrm{MPa}$ and the average yoke gap between the yoke-halves was $0.2 \mathrm{~mm}$.

The second prototype (MBP2N2) is equipped with AS collars, as per final design. For welding, a vertical load of about 660 tonnes per metre length was applied. In this case, the half-yokes are acting as a mechanical stop and it is no longer necessary to conttol the gap closure during the assembly and welding operations as it was the case in the past. Therefore, the tolerances on the half-circunforence of the shrinking cylinder shells can be increased from $0.1 \mathrm{~mm}$ to $0.5 \mathrm{~mm}$, considerably easing their series production. After MAG welding, a residual gap of $0.05 \mathrm{~mm}$ was observed; a larger weld contraction will be set for the next protolype.

Later during assombly, an axial load is applicd on the coilheads to provide a support against the axial component of the elcctromagnetic forces occurring in operation. More details about this subject are given in [6].

The 3-D measurements, based on laser tracker technology, of the MBP2N1 cold mass geometry showed that horizontal curvature and vertical straightuess [1] were achieved within $\pm 1 \mathrm{~mm}$, as requircd. The measurement of the MBP2N2 cold mass geometry is imminont.

\section{TEST RESULTS}

\section{A. Field Quality Measurements at Room Temperature}

The field-shape components of the MBP2NL cold mass were measured at room temperature, plicr to the power tests at $1.9 \mathrm{~K}$, with a excitation current of $20 \mathrm{~A}$ [7]. The results are given in Table $\Gamma \mathrm{V}$, in units of $10^{-4}$ at a reference radius $\mathrm{R}_{\text {raf }}=$ $17 \mathrm{~mm}$. They are compared to the expected values, computed for the nominal coil and hybrid yoke geometry.

The components measured in Aperture 2 differ by less that $10 \%$, from those of Aperture 1. The differences betweon the measured and the expected values of the low order harmonics, with the exception of $b_{4}$ and $b_{9}$, are within the allowed R.M.S, variation. These differences are most likely induced by inperfections of the coil gcometry. The high $b_{2}$ and $b_{4}$ values are a feature of the particular yoke of MBP2N1. The $\mathrm{b}_{2}$ value of the tominal design is 0.32 units. The high value of $b_{g}$ is not yet explained and will be investigated. The magnetic measutements at room temperature were repealed after the power tests. The valucs of the field-shape harmonics were found to be stable within $6 \%$. This indicates that the coil geometry is stable to within random movements, sce [8] for a detailed analysis. The results retative to the previous fiveblocks coil design were rather different [9], The stability of the coil was much weaker. The inilial powering and thermal cycle produced a systematic movement of $50 \mu \mathrm{m}$ of the large angle blocks of the inner coil layer in the radial outward direction.

\section{B. Power Test}

The power test campaign of the MBP2N 1 prototype statted in Match 1999 and was divided into several runs separated by a thermal cycle from $1.9 \mathrm{~K}$ to room temperature and back to $1.9 \mathrm{~K} . \mathrm{Up}_{\mathrm{p}}$ to now the magnet was quenched at $1.9 \mathrm{~K}$ in total 57 timos. The complete training quench history is shown in Fig.2.

TABLE IV

MTP2NS COID MASS, FIELD SHA PE COM PONENTS AT ROOM TEMPERATURE AND AT I $=20 \mathrm{~A}$,

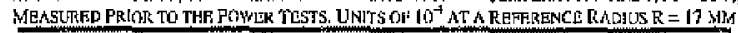

\begin{tabular}{|c|c|c|c|c|}
\hline \multirow[t]{2}{*}{ n } & \multicolumn{2}{|c|}{ Comptiled harmonics } & \multicolumn{2}{|c|}{$\begin{array}{l}\text { Measured harmonics } \\
\text { (Aportlce 1) }\end{array}$} \\
\hline & thormal & skew & nornal & skew \\
\hline 2 & 4.25 & - & 5.48 & 1.00 \\
\hline 3 & 7,32 & - & B.10 & -0.38 \\
\hline 4 & 0.00 &. & 0.66 & 0,06 \\
\hline 5 & -1.05 & - & -0.60 & -0.07 \\
\hline 6 & 0.00 & - & -0.20 & 0,02 \\
\hline 7 & 0.63 & 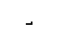 & 0.57 & 0.02 \\
\hline 8 & 0.00 & - & $-0,30$ & 0.01 \\
\hline 9 & 0.10 & - & 0.25 & -0.02 \\
\hline
\end{tabular}


During the tests the magnet was protected against quench induced damage by means of quench heaters and additionally by energy extraction to an external dump resistor. Usually $10 \%$ to $20 \%$ of the total stored energy was extracted. In the first test run the magnet was cooled maintaining from $293 \mathrm{~K}$ to $80 \mathrm{~K}$ a longitudinal temperature gradient of about $5 \mathrm{~K} / \mathrm{m}$. The first natural quench occurred at $7.35 \mathrm{~T}$ and after two more training quenches the nominal tietd of $8.33 \mathrm{~T}$ was exceeded. At the tenth quench, the magnet reached $8.9 \mathrm{~T}$, the highest value of the first tun. Subsequently, a fast thermal cycle (ditect injection of helium gas at $80 \mathrm{~K}$ ) was performed. The aim of the second run was to observe up to which field level the magnet kept a memoty of the previous training and whether the fast thermal cycle had an influence on quench beltaviour. In this run, the first quench occurred at $8.4 \mathrm{~T}$ (a $1.1 \mathrm{~T}$ gain with respect to the first run, corresponding to $66 \%$ of the $1.6 \mathrm{~T}$ increase achieved in the first run training), the highest field was $9.2 \mathrm{~T}$ at the sixteenth quench. All the 15 training quenches of the first run and 18 quenches out of 20 of the second run werc located in the transition regions of the coil ends. For the first run, quenches were located mainly in the non-connection and (NCE), while for the second run they were nuanly in the connection end (CE), submitted to bigh axial load and thermal stress during the fast cool down. Two quenches, at $8.75 \mathrm{~T}$ and $9.2 \mathrm{~T}$, occurred in the coil straight sections, during the second run only. The observed quench locations and the high axial forces measured [6] lead to the decision to remove the magnet end-cover's and reduce from 50 to $10 \mathrm{kN} / a p e r t u r e$ the design coil pre-compression at room: temperature. After the above mechanical intervention, the third run consisted of only one quench (at NCE) at a field of 7.9 T. For this quench an exceptionally high quench load of $43 \mathrm{MA}^{2}$ (instead of about $30 \mathrm{MA}^{2}$ ) was recorded. The resulting hot spot temperature and voltages across hot parts of the coil exceeded by far the values that were obsorved during the previous quenches. The hottest spot temperature was evaluated to be about $800 \mathrm{~K}$, assuming adiabatic conditions.

An analysis of the data showed that the quench detection and the energy extraction systems were working correctly, but that the current pulse delivered by the quench heater power suppliss was abnormal and did not reach the heater strips.

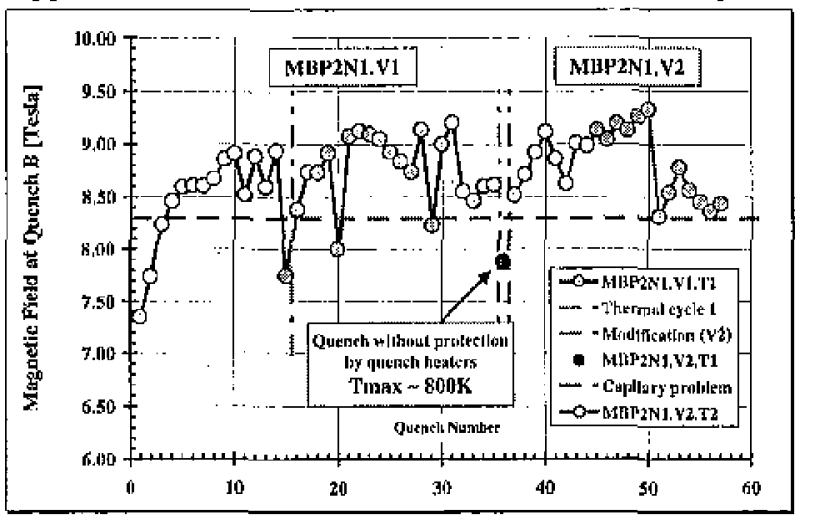

Fig. 2. MBP2N1 prototype, history of the Iraining quenches
Only the encroy extraction system protected the magnet. In fact, the heater strips were not activated because of a voltage breakdown between connector pins in the warm connection box on top of the cryostat. After repair, the magnet was cooled down and the test resumed. The first quench occurred at $8.5 \mathrm{~T}, 9 \mathrm{~T}$ was exceed after the third one and the new maximum field of $9.3 \mathrm{~T}$ was reached at the fourtecnth quench. The above performance proved the robustness of the magnet structure and its ability to withstand accidontal excessive local overheating and over-voltage without any impact on quench behaviour. The quench locations were very similar to those observed during the first two runs, with the first 13 quenches at NCE and the following eight ones at $C E$.

In conclusion, the magnet was able to exceed nominal field after three training quenches, and after thermal cycles the first quench was above nominal field. The coil end regions are limited above ultimate field $(9 \mathrm{~T})$, beyond which mechanical instabilities are triggered, leading to subsequent lower quench fields. The coil straight parts behaved reasonably well, showing only the two previously quoted glenches throughout the four power test ruts.

\section{Cold Field Quality Measurements}

'Table V reports the main results of the magnetic measurements performed in cold conditions. We report there values of the harmonics measured at injection field $(0.54 \mathrm{~T})$ and at nominal field $(8.3 \mathrm{~T})$ and integrated over the magnet length. We note first that the harmonics at high field agree reasonably well with the results of warm measurements. The sextupole, decapole and 14-pole, allowed by symmetry, are close to the values measured in warm conditions. The significant difference in the normal quadrupole can be partially explained by the effect of iron saturation (2.5 units). The comparison of the values at injection and at high field show that the partial compensation of the persistent current contribution by means of a geometric oliset on the allowed normal sextupole, decapole and 14-pole is very effective. Indeed the magnet has a better overall field quality at injection, where the beam requirements are more strict, than at high field. Finally in Fig. 3 we report the evolution of the geometric sextupole (evaluated at $5 \mathrm{kA}$ ) throughout the poweting of the first test campaign. We see that the magnet is geometrically very stable, as already shown by the results of the warm measurements before and after the test. Overall the change of normsextupole was befow 0.15 units at $17 \mathrm{~mm}$. This is three times better than in a previous $15-\mathrm{m}$ long prototype, MBP1Al also shown in Fig. 3, with a 5 block coil geometry.

\section{SCHEDULE FOR THE REMAINING PROTOTYPES}

The next four collared coils will be delivered from industry from mid October to end December 1999 so that the remaining cold mass assemblies will be tested by mid 2000 . This programme, carried out in collaboration with industry is thus overlapping with the expected beginning of series manufacture. 
TABLE V

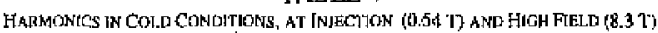
UMITS OF $10^{-4}$ AT A RER:AEHCE RADIUS $\mathrm{R}=17 \mathrm{mM}$

Injection

High field

\begin{tabular}{ccccccccc}
\hline$\pi$ & \multicolumn{2}{c}{ Aperture 1 } & \multicolumn{2}{c}{ Aperure 2 } & \multicolumn{2}{c}{ Aperture l } & \multicolumn{2}{c}{ Aperture 2 } \\
\hline & normal & skew & normal & skew & normal & skew & normal & skew \\
\hline 2 & 1.03 & 0.70 & -2.27 & 0.50 & -1.47 & 1.69 & 1.17 & 1.52 \\
3 & -0.76 & 0.08 & -0.27 & -0.30 & 6.34 & 0.12 & 6.97 & -0.12 \\
4 & 0.32 & 0.09 & -0.44 & 0.04 & 0.01 & -0.19 & -0.13 & -0.21 \\
5 & -0.05 & 0.06 & 0.21 & 0.04 & -0.97 & 0.13 & -0.93 & 0.08 \\
6 & 0.04 & .0 .00 & -0.02 & 0.01 & 0.01 & 0.21 & -0.04 & 0.22 \\
7 & 0.16 & -0.02 & 0.20 & -0.03 & 0.52 & 0.02 & 0.57 & 0.03 \\
8 & 0.02 & 0.05 & -0.01 & 0.04 & 0.02 & 0.05 & 0.00 & 0.05 \\
9 & 0.26 & -0.04 & 0.28 & -0.04 & 0.03 & -0.03 & 0.04 & -0.02 \\
\hline
\end{tabular}

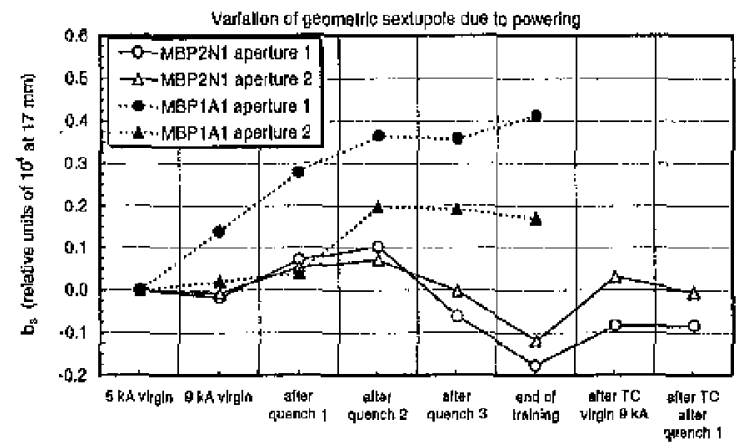

Fig. 3. Exolution of the geometric sextupole of MBP2N1 throughout the first powering catroaign, contented to the sextupole changes measured on the MBPIAl prototype.

\section{STEPS TOWARDS SERLES MANUTACTURE}

Following a call for tenders issued in December 1998 and the approval by the CERN Finance Committee in June 1999 of the contract adjudication proposals, the start of activities at the previously quoted three fitms for the manufacture of $3 \times 30$ dipole cold masses is imminent. The aim is to establish the industrial learning curve for dipole cold mass series manufacture, and to issue in the year 2001 the call for tenders for the remaining 1168 units.

Concerning the procurement of SC cables, the corresponding contracts were placed in the course of 1998 . For the dipole inner (cable D) and outer (cable 2) layers, about $3906 \mathrm{~km}$ of "Cable 1" and $3740 \mathrm{~km}$ of "Cable 2" are required, respectively. The supply of Cable 1 is entrusted to two European firms, that of Cable 2 also to two European firms for a total of $3320 \mathrm{~km}^{*}$ and to one US and one Japanese firm; each for a length of $504 \mathrm{~km}$. The SC pilot strand production has started, by end of 1999 it is expected to reception the first cable lengths from the pilot cable production (1\% of the total length).

- Main Dipoles and Quadrupolcs

\section{CONCLUSION}

The series design for the LHC dipole magnets is being validated this year with the manulacture and testing of a set of six full-length prototypes, the last of which will be cold tested by the end of spring 2000 . The performance of the first prototype, of a design close to the series one, is fulfilling the specifications required for LHC operation at the nominal field of $8,3 \mathrm{~T}$. Its performance is limited above the ultimate field of $9 \mathrm{~T}$ by the coil end regions. Design and experimental work is in progress to fully understand this linit and push it towards higher field levels. The field quality of the first prototype is rather satisfactory and its geomelry is within specifiction.

Industrial production of $\mathrm{SC}$ cables has begun, the start of the manufacture by industry of 90 dipole cold masses is imminent. The call for tenders for the manufacture of the 1142 remaining cold masses is scheduled for the year 2001.

\section{ACKNOWLEDGMENTS}

The work described here is the result of the ingenuity, professional competence, enthusiasm, untiring efforts of a large number of colleagues in the LHC and EST divisions, and of the firm and inspiring support of L.Evans.

\section{REFERENCES}

[l] C.Wyss,"LHC arc dipole status report", PAC99, New York [2] P.Fessia et al, "Selection of the cross-section design for the LHC main dipole", this Conference

[3] M.Bajko, P.Fessia, D.Perini, "Statistical studies of the tobustness of the LHC main dipole mechanical structure", this Conference

[4] K. Artoos ot al, "Status of the short dipole model program for the J.HC", this Conference

[5] J.Billan et al, "Test results on the long models and full scale prototype of the second generation L.HC are dipoles", ASC'98, Palm Spting, CA, USA

[6) K.Artoos etal,"Mensurement and analysis of axial end forces in a fu]l length prototype of the LHC main dipole magnets", this Conference

[7] S.Gleis et al.,"Analysis of the watm manetic mensurements in a LHC moin dipole prototype", this Conference

$[8] W$. Scandale et al." Influence of mechanical tolerances or field quality in the LHC mait dipole", this Conference

[9] O. Pagano et al, LHC Project Note 180, 1999 